\title{
Amyand Hernia
}

\author{
Prof Dr N Murugesan M.S, Prof Dr Rajasekaran M.S, \\ Dept Of GL Surgery Sri Laxminarayana Institute of Medical Sciences -Puduchery,South India
}

\begin{abstract}
Amyand hernia is presence of caecum \& appendix inside the hernia sac,[2] Mostly inguino scrotal hernias and rarely femoral,incisional, umbilicaland spigelian hernias[Table 1]. The patients report themselves as emergency case because of varying grade of pain precipitated by obstruction, incarceration, strangulation and perforation. Age and sex are not a definitive yardstick.Cases were reported from newborn to above 80 yrs in both sexes. Clinical diagnosis is puzzling. Correct diagnosis is arrived at operation table. This hernia is named after the surgeon Amyand who performed the first appendicectomy in a childs' complicated inguino scrotal swelling and sinus, the sac of which contained discharges of perforated appendix [1]

Keywords: Inguino scrotal swellings- sliding hernias-content caecum \& appendix-Amyand hernia-painpaediatric,geriatric,adolescent age group- causes- complications -diagnostic access.-Treatment
\end{abstract}

\section{Introduction}

Rare cases are often encountered in clinical practice.Inguinal hernias are reported in surgery op as a routine.Hernia acquires significance when the content is appendix and other visceras.Herein a Right side congenital indirect inguinalhernia in a 5 yr old boy containing appendix inside hernial sac is presented .[Fig 1]

\section{Case summary}

Five yr old male boy attended the surgical op with complaint of RT inguino scrotal swelling since birth.Pain wass felt on and off recently.Swelling was also increasing in size.His physical indices were of standard value except moderate anaemia and average nutritional profile. There is no thyroid malfaction. Mile stones were normal. Both side testes were palpable separately. The swelling was partly reducible with gargle sound[Fig 1] .,Soft and mildly tender. Cough impulse was elecitable.Transillumination was negative. Left side was normal. Systemic examination - normal.Clinically the case was judged as congenital incarcerated inguinal hernia.Emergency attention was accorded [5].US Scan- inguinoscrotal region - was suggestive of congenital indirect inguinal hernia rt side. The content was small intestine loops and omentum.

Basic investigations, $x$ ray chest,pulse, BP and temperature were within normal limits.

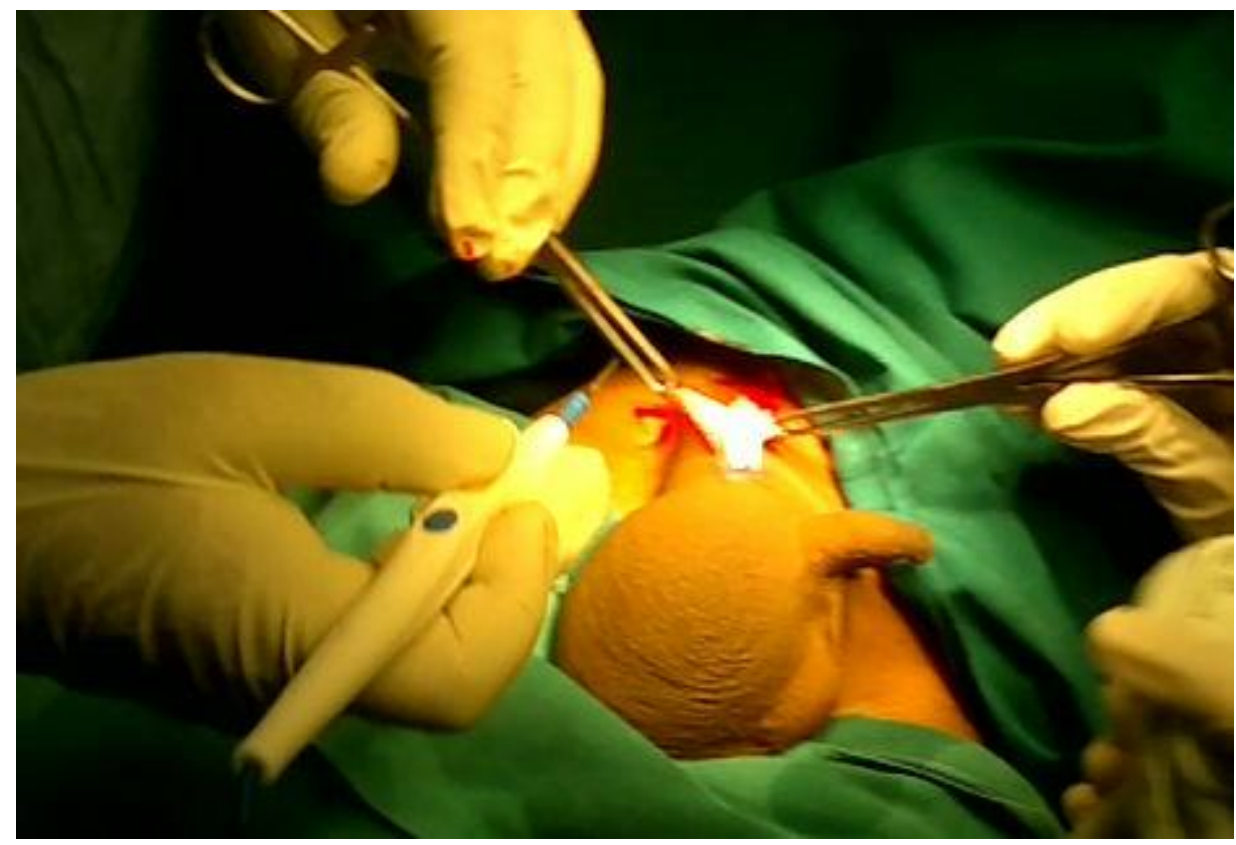

Fig 1 'Inguino scrotal swelling rt side.Extended lower inguino scrotal incision.

To open inguinal canal' 
Emergency surgery was planed. Under G A Inguinal canal was approached through extended inguino scrotal incision. External ring was divided,dissection was proceeded from downwards to obliquely upwards towards the internal ring.Fibrous bands at external and internal rings were released.The sac was opened in the middle.Turgid elongated appendix of $10 \mathrm{cms}$ length disproportionate to the age was sprout out [Fig 2].The caecum \& appendix were closely adherent to the posterior wall of the sac.By meticulous dissection adhesions were released . Card structures were separated from the sac,followed by appendicectomy and herniotomy. Wound was closed without inguinal canal repair. Post operative period was uneventful.Sutures were removed on $7^{\text {th }}$ POD and dis charged with advice to attend review op periodically to watch for recurrence.

\section{Discussion}

The presence of vermiform appendix, whether inflamed or not, inside a hernia sac is called as Amyand's hernia. This rare condition constitutes $1 \%$ of all the inguinal hernias, whereas inflamed appendix is found in only $0.1 \%$ of the cases.[1] In pediatric patients, it can be mistaken for incarcerated/strangulated hernia, torsion of testis, or scrotal abscess.Claudus Amynad a French exile in Britain, Surgeon to King George II first did the appendicetomy on a $11 \mathrm{yr}$ old boy Hanvel Anderson who was examined for discharging faecal fistula in the rt inguinoscrotal hernia on 6/12/1735 [ 1\&2 ]

As such some hernias are named according to the content of hernia sac, site of occurrence etc. Litres,Mydyl's hernias and Amyand hernia are named after their contents, meckels diverticulam, portion of surface of the small intestinal loop and appendix respectively..others are femoral, incisional and interstitial hernias etc [Table1],[13] The single case presentation is illustrating paediatric rt side congenital inguinal hernia and the content being inflamed appendix [Fig 2].A pilot study of congenital paediatric hernia by a team in Karnataka highlighted some interesting facts. The present prospective, hospital based study was undertaken in the Department of Surgery, in Hubli, Karnataka State, for a period of one year between July 2001 to June 2002. [14]A total of 960 cases were admitted in paed surgy ward.out of 960 cases 50 were cong inguinal hernias. Breakwise particulars are as follows.

Hernia type

Bilat Ing hernia

Rt cong Ing Hernia

Obstructed hernia

Lt cong Ing hernia

\section{Frequency}

20

Male Female ratio- 47 and 3. Type of birth-Term 35,Preterm 15. Age wise incidence-.1-5yrs -26; 5-10 yrs 12 ; more than $10 \mathrm{yrs} 6$.

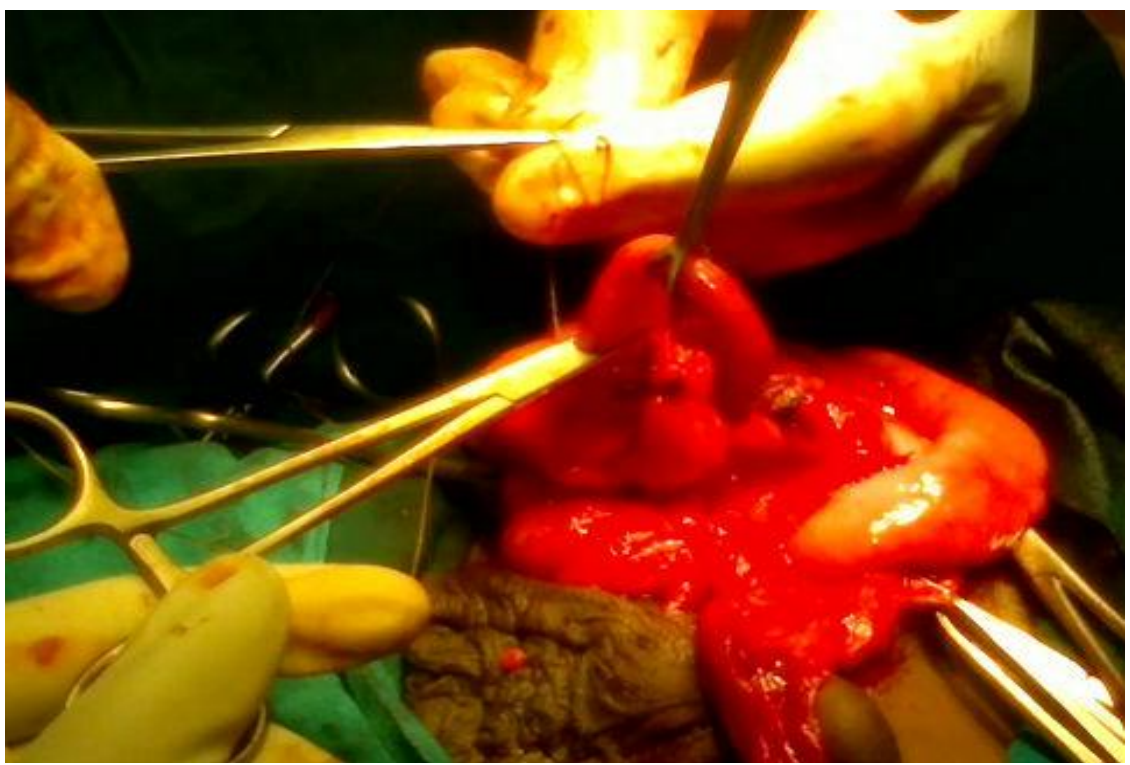

Fig 2- 5 yr old boy - 'RT Inguinal Hernial sac, opened.'

'Abnormal appendix , found inside hernial sac'.

Amyand hernia is encountered in both extremes of life. Etiopathogenesis revolves round status of deep inguinal ring,strength of muscle and fascia [T-S-D ,Type,Staging ,Dimension] of abdominal wall,error in rotatation of gut,intermesentric fat deposition, abundant retroperitoneal fat,intrabdominal pressure and kinking of 
appendix lumen at the internal ring level are construed to be the causes of Amyand hernia.[ 10]., In paediatric patients as anterior abdominal wall muscles which take part in the formation of inguinal canal and internal and external rings are in developing status and yet to get desirable strength, the descending testis has liberal freedom to drag the process vaginalis to which the appendix herniates. In old age there is laxity of muscles, internal ring becomes patulous, widening of inter mesenteric space and retroperitonium due to fat deposition and increased intra abdominal pressure due to obesity and cough precipitated by chronic bronchitis and constipation,dysuria due to BHP. This pathophysiology acts as driving force to push the appendix into the hernia sac.The appendix inside hernia sac is subjected to kinking at the deep ring level and vulnerable to trauma on the anterior abdomen wall which reduces blood supply to appendix.later seconday appendicitis is precipitated [11]. Further, etiopathogenesis of amynad hernia is attributed to 1 mobile nature of caecum and appendix, 2 anatomical placement is in close proximity to internal ring which is wide and patulous 3 Drawn to vaginal process actively by means of connection with the testis 4 During fourth month of development caecum descends to RIF. Adhesions between caecum,appendix and posterior peritoneum covering developing testis are observed.Subsequent descent of process vaginalis and testis into the inguinal canal will draw the appendix into the inguinal canal [18].Perforation,abcess,sinus formation and peritoneal blow outs are anticipated treaded complications [17,-18,20]. Watson showed that appendix was present in 1 to $1.5 \%$ of all inguinal hernias.Hoffman and Fromme reported after studying 8692 cases of inguinal hernia that appendix was found in 11 cases- $0.13 \%$. According to A C Wood Amyand hernia scored $0.19 \%$ of 3084 hernial cases taken up for review.Leigh Watson in 1923 reviewed 512 cases of hernia of appendix including femoral, incisional and umbilical in addition to inguinal [Table 1].Out of 512 cases he observed that inguinal hernia containing appendix was 269. Among 242 inguinal appendix hernias Male ,Female distribution was218, 24 respectively. Rt side 230 Left 19 among 249 samples.[18]

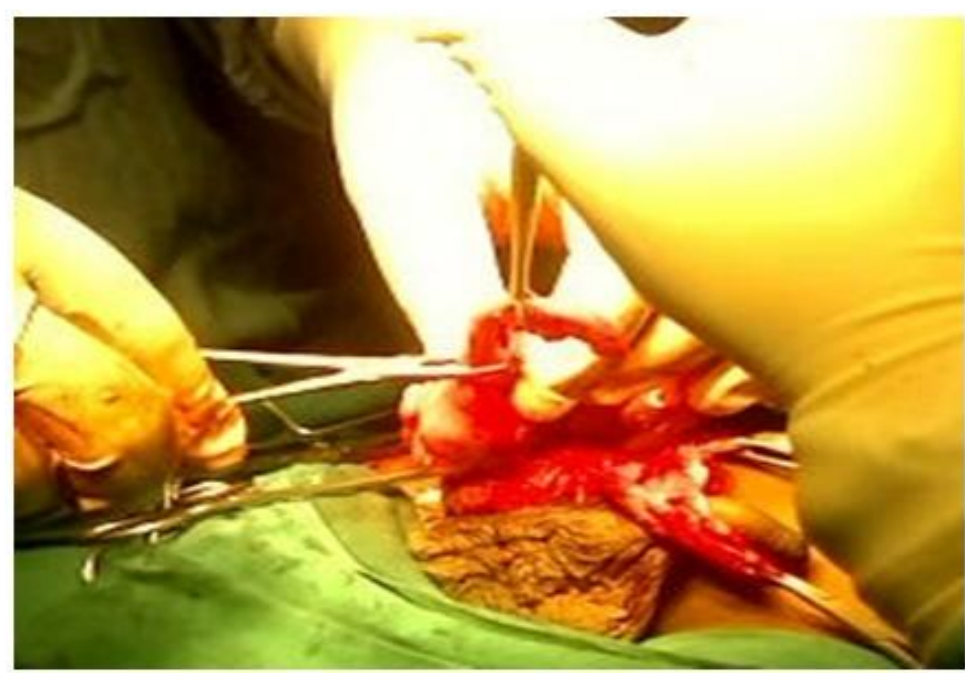

Fig 3.'Elongated inflamed, turgid appendix ,freed from mesentery and adhesions inside hernial sac.' Proceeded for Appendicectomy.

Department of Surgery, Whiston Hospital, Prescot, Merseyside, UK. Conducted elaborate study on 18 consecutive cases over a period of 15 yrs.from 1991 to 2005. The following results were obtained.There were 17 men and one woman. Their median age was 42 years.. The commonest presenting symptom was painful inguinal or inguino-scrotal swelling (83\%). All patients, therefore, underwent emergency surgery with a presumptive diagnosis of either incarcerated or strangulated inguinal hernia. Operative findings included 11 normal appendices, four inflamed appendices [Fig 3] and three perforated appendices in the inguinal hernial sac.[15] Different teams conducted similar studies at different times and at different Health care centres. Between 1998-2006,1090 inguinal hernias were reported in Dept of paediatric surgery, medical school of Cumhuriet varsity, Turkey.The following break up of profiles were recorded.Age ranged from 15 days to 14 months.12 patients had amyand hernia.Operative findings were- normal appendix 2,inflamed 6, serosal aberation 4.[9] Amynad is rarely encountered in the left side due to situs inversus and mobile caecum[ 6-9]

The patients reported as either obstructed or strangulated hernias in the op dept for emergency treatment [Fig 1].In Italy 82 yr old female attended emergency medical service provider with signs and symptoms of intestinal obstruction and strangulation originating from inguinal hernia.Emergency Laparotomy revealed inflamed appendix in Rt side Amyand hernia [Fig 2] and also necrotized ileal loop. Appendicectomy,resection and end to end anastomosis of ileal loop was done.[17] 
Table 1

Classification of Amyand Hernias, After Losanoff and Basson, modified by Rikki (ㅁ) as Rikki's classification of Amyand Hernias[12]

\section{Classification Description}

Type $1 \quad$ Normal appendix within an inguinal hernia

\section{Surgical management}

Hernia reduction, mesh repair, appendicectomy in young
Type 2

Type 3

Type 4

Type - 5 a

Type - 5 b

Type - 5 c
Acute appendicitis within an inguinal hernia, no Appendicectomy through hernia, abdominal sepsis primary repair of hernia, no mesh abdominal wall, or peritoneal sepsis repair of hernia, no mesh

Acute appendicitis within an inguinal hernia Manage as types 1 to 3 hernia, related or unrelated abdominal pathology investigate or treat second pathology as appropriate

Appendicectomy through hernia, primary repair of hernia including mesh

Acute appendicitis within an incisional hernia, no Appendicectomy through hernia, abdominal sepsis primary repair of hernia

Acute appendicitis within an incisional hernia, abdominal wall, or peritoneal sepsis or in relation Manage as type - 4 to previous surgery

\section{Diagnostic problems}

Preoperatively Amyand hernia can not be diagnosed easily.US Scan inguinal region and abdomen only hints the inflammatory changes inside the sac. Only CECT and MultiDetector CT can capture the morbid anatomy of Amynad hernia and contents.[13] Haemogram only displayed mild to moderate leucocytosis Other investigations are not of much help to decide diagnosis and treatment. In the absence of CECT \& MDCT Surgery is indicated only on presumptive incarcerated and strangulated hernia conclusion [Fig 1].

Choice of surgical management . Choice of operation is appendecectomy if ther is inflammation[FIG 2\&3], followed by herniotomy and inguinal canal repair in the case of adults and aged.Appendicectomy is deferred if there is no inflammation. For paediatric cases reduction of contents, herniotomy and closure without repair is prefered.Appendicectomy is reserved,[decided on merit.]However second opinion is reasonably advised. Ofili reported two cases of appendicitis in the follow up period of 11 Herniaraphy operations indicated for Amynad hernia in whom appendix was preserved.Hence he advocated incidental appendicectomy to all cases of Amynad hernia regardless of inflammation or absence of inflammation [21].

Post operative follow up is mandatory for a period of two yrs because of more incidences of recurrence[12].The article is presented to signal alert to practicing surgeons about Amyand hernia and it's impending complications and decision for correct treatment while they are dealing different hernias.

\section{References}

[1]. J R Soc Med. 1993 February; 86(2): 104-105.

[2]. Amyand C.: Of an inguinal rupture, with a pin in the appendix coeci,incrusted with stone; and some observations on wounds in the guts.Phil TransRoyal Soc, 1736, 39: 329 Journal of Paed Surgery 1991; 265 - 83

[3]. Brief Communications and case reports,Hernia of Appendix , Ann Surg V .106 [1] July 1937,135-146

[4]. JBR-BTR, 2007, 90: 524-525. AMYAND'S HERNIA: INGUINAL HERNIA WITH ACUTE APPENDICITIS S. Laermans, P. Aerts, R. De Man1

[5]. Hernia (2002) 6: 137-140DOI 10.1007/s10029-002-0065-1 Sliding hernias R.Bendavid Gupta S, Sharma R, Kaushik R. Left sided Amyand's hernia. Singapore Med J. 2005; 46:424-5. [PubMed]

[6]. Breitenstein S, Eisenbach C, Wille G, Decurtins M. Incarcerated vermiform appendix in a left-sided inguinal hernia. Hernia. 2005;9:20-2.

[7]. Malik KA. Left sided Amyand's hernia. J Coll Physicians Surg Pak. 2010; 20:480-1. [PubMed]

[8]. Maedica (Buchar). 2011 October; 6(4): 321-327. Amynad hernia Pathophysiology,Role of investigations and Treatment JIAPS 2012 July- sep 17[3] 128,129 Maedica A Journal of Clinical Medicine, Volume 6 No.4 2011

[9]. Constantine S. Review of literature- Computed Tomography Appearances of Amyand Hernia. J Comput Assist Tomogr. 2009;33:359-62. [Pub Med] Fukukura Y., Chang S.D.: Acuteappendicitis within a femoral hernia:multidetector CT findings. Abdominal Imaging, 2005, 30: 620-622.

[10]. Journal of Clinical and Diagnostic Research, 2012. V. Ravikumar et al.,Clinical study of Inguinal Hernia

[11]. Amyand's hernia: a report of 18 consecutive patients over a 15-year period.Sharma H, Gupta A, Shekhawat NS, Memon B, Memon MA.Department of Surgery, Whiston Hospital, Prescot, Merseyside, UK. Hernia. 2007 Feb;11(1):31-5. Epub 2006 Sep 26. 
[12]. PMID-18427448 PUBMED-Indexed for MEDLINE A rare presentation of Amynad HerniaAnn Surg V .106 [1] July 1937 ,135146, PMC1390543

[13]. Coulier B, Pacary J, Broze B. Sonographic Diagnosis of Appendicitis within a Right Inguinal Hernia (Amyand's Hernia). J Clin Ultrasound. 2006;34:454-57. [PubMed]

[14]. J Indian Assoc Pediatr Surg. 2012 Jul-Sep; 17(3): 128-129.doi; 10.4103/0971- 9261.98134 - PMCID: PMC3409903 Amynad hrnia presented as chronic scrotal sinus Ethiop. Med.Journal 1991,29-37-8

\section{Acknowledgement}

Our sincere thanks to the management,Dean, \& Medical Director for granting permission to use the clinical materials and publish the same in IOSR Journal 